\title{
A Trajectory-Based Investigation of Physical and Dynamical Processes That Govern the Temporal Evolution of the Subtropical Jet Streams over Africa
}

\author{
OLIVIA MARTIUS \\ Oeschger Centre for Climate Change Research, and Institute of Geography, University of Bern, Bern, and Institute \\ for Atmospheric and Climate Science, ETH Zurich, Zürich, Switzerland \\ HEINI WERNLI \\ Institute for Atmospheric and Climate Science, ETH Zurich, Zürich, Switzerland
}

(Manuscript received 20 July 2011, in final form 14 December 2011)

\begin{abstract}
Tropical, subtropical, and extratropical dynamical processes govern the synoptic-scale evolution of the subtropical jet stream(s) over Africa. However, the relative importance of the respective effects is still under debate and is the focus of this study. Interim ECMWF Re-Analysis (ERA-Interim) data are used to calculate backward trajectories from the subtropical jet over Africa during winter 2005/06. The trajectories allow for studying the jet dynamics from both a potential vorticity (PV) and an angular momentum point of view and for linking the two theoretical frameworks.

Three cases of synoptic-scale Rossby wave breaking in the extratropics and subtropics are presented in detail. They illustrate basic flow configurations where (i) the subtropical jet is mainly forced by tropical dynamics, (ii) extratropical forcing contributes substantially to the jet acceleration, and (iii) strong diabatic processes in the subtropics impact the jet.

The case study results are then generalized for the entire winter season. The main findings are as follows: (i) Approximately $41 \%$ of the trajectories reach the subtropical jet from the deep tropics and for these trajectories the nonconservation of angular momentum $M$ due to eddy forcing leads to a decrease of $M$ by about $5 \%$. (ii) A nonnegligible fraction of roughly $18 \%$ of the trajectories reaches the subtropical jet from the extratropics. (iii) Wave breaking is instrumental for bringing extratropical, high-PV air southward. (iv) Diabatic processes in the subtropics have a negligible direct effect on the upper-level PV. This is in contrast to observations from the extratropics and might be the consequence of the small planetary vorticity in the tropics and subtropics.
\end{abstract}

\section{Introduction}

Upper-level westerly jet streams are ubiquitous and important features of the subtropical atmospheric flow. On relatively short time scales (up to a few days) these jets serve as waveguides for synoptic-scale Rossby waves, which in turn can trigger high impact weather events (e.g., Martius et al. 2008; Feldstein and Dayan 2008). With regard to the transport of chemical constituents, the subtropical jets can act as local barriers for meridional exchange (e.g., Shuckburgh et al. 2009) but also

Corresponding author address: Olivia Martius, Institute of Geography, University of Bern, Hallerstrasse 12, Bern CH-3012, Switzerland.

E-mail: olivia.martius@giub.unibe.ch coincide with areas of frequent tropopause folding and attendant enhanced vertical exchange between the stratosphere and the troposphere (Sprenger et al. 2003). On decadal time scales observations reveal a poleward shift of the climatological zonal mean subtropical jet in conjunction with a widening of the tropical belt (Seidel et al. 2008, and references therein). However, regionally a southward shift of the subtropical jet over the eastern North Atlantic and Africa is observed between 1958 and 2002 in conjunction with a positive North Atlantic Oscillation index during the last decades of the twentieth century (Isotta et al. 2008). Although jet streams in the subtropics appear as a prominent climatological feature (e.g., Koch et al. 2006), their location, size, and amplitude are characterized by variability on synoptic time scales. The jet variability on the climatological time scale 

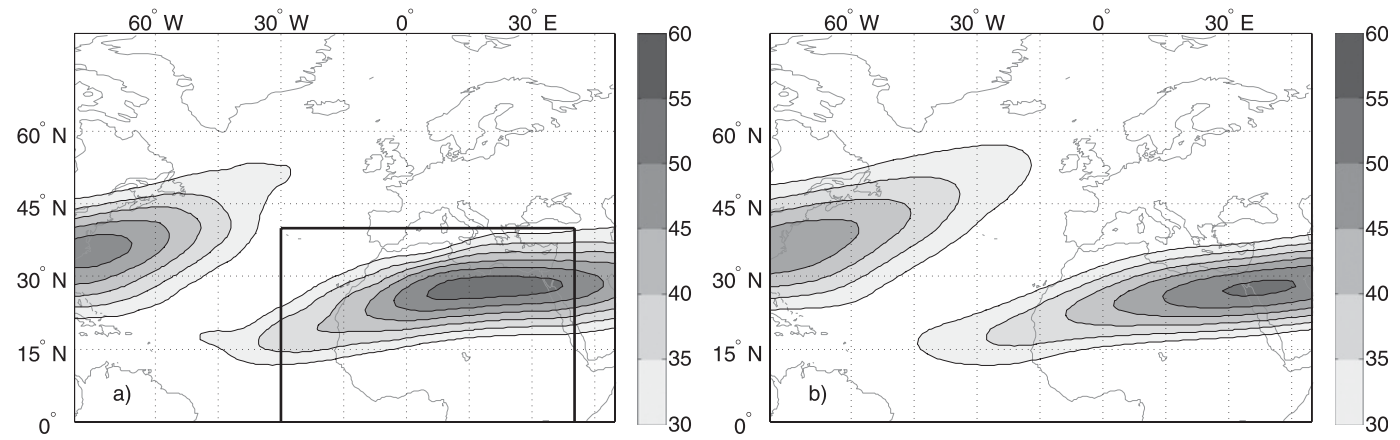

FIG. 1. Wind velocity $\left(\mathrm{m} \mathrm{s}^{-1}\right.$ ) at $200 \mathrm{hPa}$ (a) winter [December-January (DJF)] 2005/06 mean and (b) ERAInterim 1989-2009 DJF mean. The black rectangle indicates the area used for the selection of the subtropical jet trajectories.

results from subtle forcing effects of slow-varying boundary conditions (e.g., sea surface temperatures) on the synoptic variability.

In the literature, a distinction is often made between two types of upper-level jet streams: eddy-driven jets and subtropical jets (e.g., Reiter and Whitney 1969; Lee and Kim 2003). Koch et al. (2006) proposed an alternative jet stream typology with two categories of shallow and deep jets based on the depth of the baroclinic zone associated with the jet. Eddy-driven ("deep") jets are sustained primarily by baroclinic eddies and they can form in an initially jet-free atmosphere through the stirring by baroclinic eddies only (e.g., Lee 1997). The eddy-driven jets are located in areas with strong surface baroclinicity in the extratropics. Subtropical ("shallow") jets are located at the poleward edge of the Hadley cell and owe their existence in a first approximation to the transport of angular momentum from the tropics into the subtropics (e.g., Held and Hou 1980). It has been shown that subtropical eddies can significantly affect the conservation of angular momentum and hence the evolution of subtropical jets (e.g., Vallis 2006, and references therein; Bordoni and Schneider 2010). Besides the important influence of subtropical eddies, waves propagating on the extratropical jet can instigate waves on the subtropical jet and hence influence the latter's dynamics (Martius et al. 2010). This link between the two jets is particularly strong if the wave on the extratropical jet undergoes wave breaking. It remains an open question, though, how relevant the extratropical forcing of the subtropical flow is on a climatological time scale. The general objective of this study is to further our understanding of the synoptic-scale dynamics that govern the temporal evolution of subtropical (typically shallow) jet streams over North Africa.

In the winter season, in the longitudinal sector from approximately $60^{\circ} \mathrm{W}$ to $0^{\circ}$ a double-jet configuration is found in the time mean (see Fig. 1 and Koch et al. 2006).
A clear latitudinal separation of the eddy driven (or deep) and the subtropical (or shallow) jet exists during this season. The wintertime jet streams over North Africa are hence clean examples of subtropical (shallow) jets in the Northern Hemisphere and it is therefore instructive to study their dynamics and to elucidate how they are affected by synoptic-scale tropical, subtropical, and extratropical processes.

The dynamics of jets can be studied by adopting complementary theoretical frameworks. Here we will apply two perspectives based on potential vorticity (PV) and angular momentum. In the PV perspective, the wind speed on an isentropic surface is directly proportional to the (quasigeostrophic) isentropic PV gradient (e.g., Davies 1981; Schwierz et al. 2004). To understand the temporal evolution of the subtropical jet stream it is therefore illuminating to investigate processes that lead to a change in the isentropic PV gradient across the subtropical jet stream, by modifying either the tropospheric low PV along the equatorward edge of the jet or the stratospheric high PV along the poleward flank of the jet. The following processes could potentially contribute significantly to such changes of the isentropic PV gradient: (i) the isentropic stirring of air masses with differing PV by synoptic-scale breaking eddies and the attendant formation of areas with strong PV gradients in the extratropics and the subtropics, (ii) the quasi-isentropic advection of air with low PV from the tropics, and (iii) the diabatic depletion of upper-level PV by strong convective processes in the subtropics and tropics (e.g., Kiladis 1998). The diabatic depletion of upper-level tropospheric PV is potentially very important since the gradients of the quasigeostrophic and the Ertel PV scale logarithmically (e.g., Martius et al. 2010) and small changes of low Ertel PV values have hence a significant effect on the jet.

The second perspective is based on the material conservation of angular momentum, which indicates that 
the upper-level export of air from the deep tropics in the poleward-directed branch of the Hadley cell is an important forcing mechanism of the subtropical jet. For instance, an air parcel starting with zero zonal wind speed at $10^{\circ} \mathrm{N}$ would be accelerated to approximately $38 \mathrm{~m} \mathrm{~s}^{-1}$ if moving to $20^{\circ} \mathrm{N}$, and to approximately $87 \mathrm{~m} \mathrm{~s}^{-1}$ if reaching a latitude of $30^{\circ} \mathrm{N}$ (Fig. 2).

Angular momentum is materially conserved for frictionless flows that do not experience zonal pressure gradients, as expressed by the following equation based on the conservation of zonal momentum (Gill 1982):

$$
\frac{D M}{D t}=-\frac{1}{\rho} \frac{\partial p}{\partial \lambda}+r \cos (\varphi) V_{\lambda}
$$

Here $M$ is the angular momentum per unit mass, defined as $M=u r \cos (\varphi)+\Omega r^{2} \cos ^{2}(\varphi) ; r$ is the radius of the earth; $\lambda$ and $\varphi$ are longitude and latitude, respectively; $\Omega$ is the rotation velocity of the earth; and $V_{\lambda}$ is the viscous term, which will be neglected in the subsequent considerations. The first term on the right-hand side of the equation describes the nonconservation effect of zonal pressure variations (eddies). Assuming geostrophic balance, an air parcel in the Northern Hemisphere is transported northward along a positive longitudinal pressure gradient (e.g., along the eastern edge of a trough) and at the same time experiences a reduction of angular momentum. This will reduce the acceleration of polewardmoving air parcels compared to the first-order estimate given in Fig. 2. In this study, we aim to quantify the magnitude of this reduction by considering the flow evolution along air parcel trajectories feeding into subtropical jet streams. Note that for an equatorwardmoving air parcel, the longitudinal pressure gradient is negative (again assuming geostrophic balance), leading to an increase in angular momentum.

Both the angular momentum and the PV perspective will be used to study the dynamics of a selection of subtropical jets in detail. Three synoptic episodes will be considered that occurred during the Northern Hemisphere winter of 2005/06 to illustrate and quantify different forcing mechanisms of subtropical jets using Lagrangian and Eulerian analysis techniques. With this approach we aim at addressing the following three main objectives of this study:

1) Identify and quantify tropical, subtropical, and extratropical synoptic-scale processes that affect the intensity of subtropical jets.

2) Quantify the relative importance of adiabatic dynamics (e.g., large-scale isentropic advection) and diabatic processes (e.g., modification of the isentropic PV gradient by latent heat release) for subtropical jet intensification.

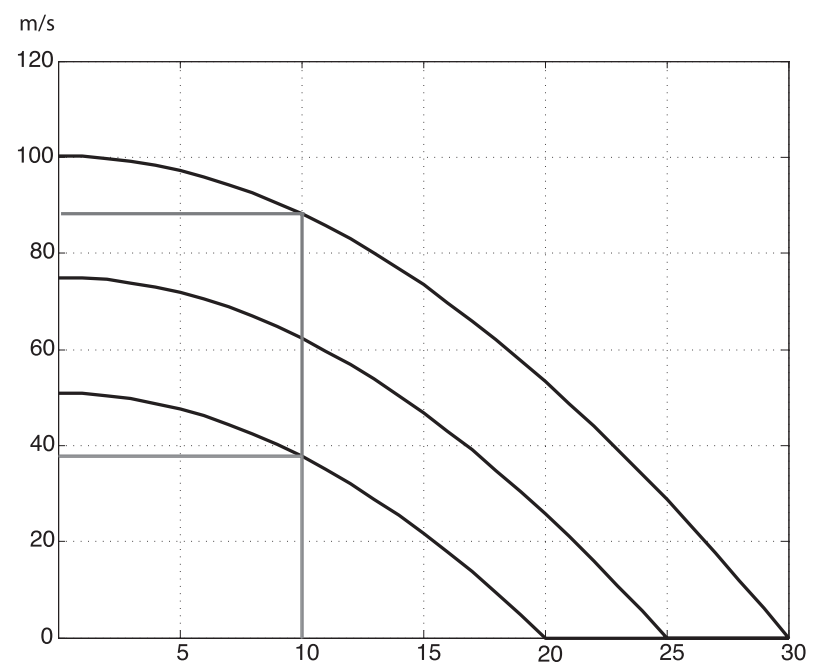

FIG. 2. Illustration of the flow acceleration of a northwardmoving air parcel due to angular momentum conservation assuming that the air parcel has a starting zonal wind speed of $0 \mathrm{~m} \mathrm{~s}^{-1}$. The black lines indicate the latitude of the jet (i.e., the final latitude); values on the $x$ axis give the starting latitude and the $y$ axis the zonal wind speed. The gray lines indicate two examples. An air parcel starting at $10^{\circ} \mathrm{N}$ reaches the jet at $20^{\circ} \mathrm{N}$ with a wind speed of $37.8 \mathrm{~m} \mathrm{~s}^{-1}$. An air parcel starting at $10^{\circ} \mathrm{N}$ and reaching the jet at $30^{\circ} \mathrm{N}$ has been accelerated to $87 \mathrm{~m} \mathrm{~s}^{-1}$.

3) Establish a synthesis of the complementary theoretical perspectives based on PV and angular momentum for an improved understanding of the synoptic-scale modification of subtropical jets.

The remainder of this paper is organized as follows: the details of the Lagrangian approach are specified in the next section. Section 3 discusses three episodes of subtropical jet formation, followed by generalization of the case study results in section 4 . The final section provides a discussion of the results and some concluding remarks.

\section{Data and methods}

Interim European Centre for Medium-Range Weather Forecasts (ECMWF) Re-Analysis (ERA-Interim) data (Dee et al. 2011) have been used for all analyses. The data are available every $6 \mathrm{~h}$ on 60 vertical levels and were interpolated from a T255 spherical representation to a regular grid with $1^{\circ}$ horizontal resolution. Three-dimensional fields of Ertel PV, the zonal pressure gradient, and angular momentum were calculated from the three-dimensional wind and temperature fields.

Trajectories were calculated with the Lagranto trajectory tool developed by Wernli and Davies (1997). Backward trajectories were started every $6 \mathrm{~h}$ between 1 December 2005 and 28 February 2006 on a horizontal grid with 50-km resolution at all grid points where wind 
velocity exceeded $40 \mathrm{~m} \mathrm{~s}^{-1}$ on the $340-$ and $345-\mathrm{K}$ isentropic levels in a rectangular domain over northern Africa $\left(0^{\circ}-40^{\circ} \mathrm{N}, 30^{\circ} \mathrm{W}-40^{\circ} \mathrm{E}\right.$; see Fig. 1). The $345-\mathrm{K}$ isentrope lies close to the $200-\mathrm{hPa}$ level during winter, which climatologically corresponds to the level of maximum wind velocity. The trajectories were calculated back in time for $144 \mathrm{~h}$.

Along with the three-dimensional pathways of the air parcels, the trajectory algorithm traced the specific humidity $q$, the horizontal wind components $u$ and $v$, the potential temperature $\theta$, the equivalent potential temperature $\theta_{e}$, diabatic heating due to condensation (DHR), the angular momentum per unit mass $M$ and the derivative of pressure in the longitudinal direction [first term on the right-hand side of Eq. (1)]. The DHR has been calculated diagnostically in an approximate way as outlined briefly in Rossa et al. (2000).

Some air parcel trajectories pass through regions of very active tropical convection, which might significantly reduce the accuracy of the trajectories due to the unresolved nature of vertical motion associated with deep convection. Ploeger et al. (2011) showed that the ERAInterim dataset is reliable for trajectory calculations in the tropics. This is confirmed by a visual comparison of the trajectory results with IR satellite pictures showing that even if the ERA-Interim data are not capable of resolving individual convective up- and downdrafts, the dataset appears to qualitatively capture the vertical motion within larger (organized) convective systems.

\section{PV mixing and angular momentum transport by wave breaking}

\section{a. Extratropical synoptic-scale wave breaking}

Subtropical jets can be affected by synoptic-scale wave breaking in the extratropics. The breaking waves bring stratospheric high-PV air equatorward and thereby enhance the PV gradient across the subtropical waveguide locally. This process can be viewed as mixing through wave breaking (e.g., McIntyre and Palmer 1983; Dritschel and McIntyre 2008) whereby a PV gradient distribution that is relatively uniform with latitude prior to the mixing event is rearranged by the breaking wave into two areas of strong gradients to the south and to the north separated by a well-mixed area in the center. Relevant for the subtropical jet is the sharpening of the PV gradient to the south of the breaking wave and the attendant flow acceleration (Held and Phillips 1990).

An example of an anticyclonically extratropical breaking wave sharpening the PV gradient in the subtropics and thereby accelerating the subtropical jet is shown in Fig. 3. The four panels illustrate the time evolution of the dynamical tropopause over the North Atlantic and the jet on the $345-\mathrm{K}$ isentrope over North Africa between 0000 UTC 3 January 2006 and 1800 UTC 4 January 2006. A synoptic-scale wave broke during this time period over Europe. The breaking wave can be identified on the 320-K isentropic surface (blue line in Fig. 3). Because of the breaking wave, high-PV air approached the subtropical jet from the north and thereby enhanced the PV gradient locally across the jet. Consistently the subtropical jet over Africa strengthened. The maximum wind velocity over Africa increased from 62 to $73 \mathrm{~m} \mathrm{~s}^{-1}$ over the 42-h period. The wave breaking event in the extratropics did not affect the fairly zonal character of the subtropical dynamical tropopause (red and green lines in Fig. 3).

The trajectory analysis helps to link the PV-based interpretation and the angular momentum perspective of this episode. Back trajectories initiated at the jet over Africa at 1800 UTC 4 January illustrate that the air parcels reaching the jet originated mainly from the tropics and subtropics (Fig. 4). The air parcels followed roughly three different pathways. One strand of trajectories moved eastward in the subtropics at almost constant latitude passing a weaker jet streak upstream over the central Atlantic (Fig. 4a). More than half of the trajectories followed this pathway. The PV values of these trajectories ranged from approximately 0.5 to 3 potential vorticity units $\left(\mathrm{PVU} ; 1 \mathrm{PVU}=1 \times 10^{-6}\right.$ $\mathrm{K} \mathrm{kg}^{-1} \mathrm{~m}^{2} \mathrm{~s}^{-1}$ ) at the time when they reached the subtropical jet over Africa (Fig. 4b), indicating that air parcels in the stratosphere and the troposphere followed a similar path. The PV values were fairly well conserved along the trajectories.

A second strand of trajectories containing approximately a third of the trajectories originated from the equator and moved poleward comparatively slowly along the western edge of a weak anticyclonic streamfunction anomaly over Africa (Fig. 4c) and a transient anticyclonic streamfunction anomaly over the western Atlantic (not shown). It is likely that the pathways of the air parcels and the appendant anticyclonic streamfunction anomaly were forced by convective heating over equatorial Africa and the central Atlantic in early January (not shown), since the trajectories followed the canonical flow pattern forced by tropical heating, namely a divergent latitudinal flow at upper levels that is deflected anticyclonically in the subtropics (e.g., Matsuno 1966; Gill 1980; Hoskins and Karoly 1981). The trajectories reached the tropospheric part of the subtropical jet and the PV of these air parcels was very low. A more detailed analysis of these tropical trajectories shows that a minority of trajectories ascended from the surface to the tropopause in areas of intense convection over the central Atlantic, while the majority of the tropical trajectories were located at upper levels for the entire 144-h time period (not shown). 

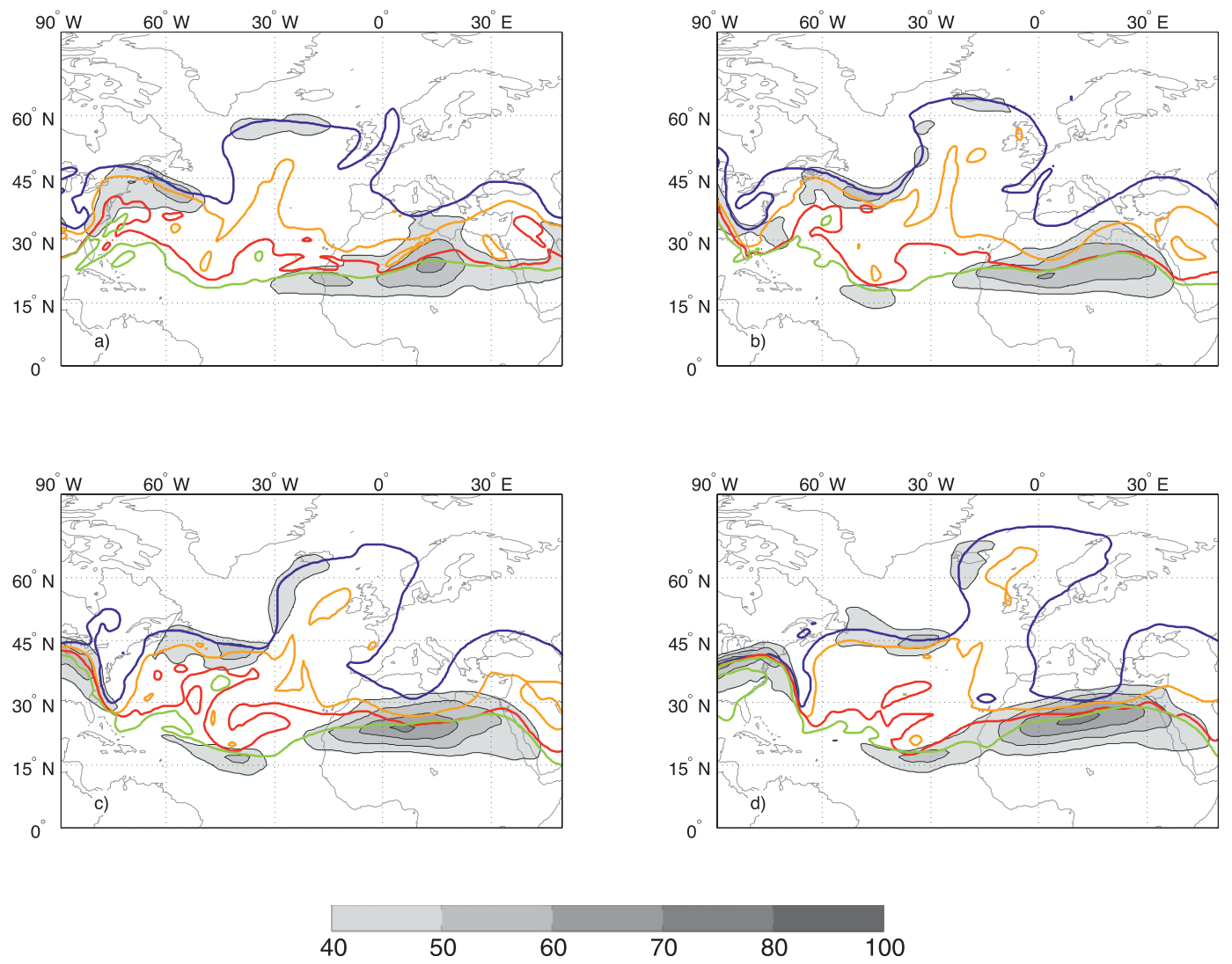

FIG. 3. Wind velocity on the $345-\mathrm{K}$ isentropic surface (gray shading) and the dynamical tropopause (2-PVU contour) on the 320- (blue), 330- (yellow), 340- (red), and 350-K (green) isentropic surface, at (a) 0000 UTC 3 Jan, (b) 1200 UTC 3 Jan, (c) 0000 UTC 4 Jan, and (d) 1800 UTC 4 Jan.

A third strand of trajectories with very few members joined the stratospheric part of the subtropical jet coming from the north. The convergence of tropical low-PV air and subtropical and extratropical stratospheric high-PV air in the subtropical jet is visible in Fig. 4b.

The next step is to reconcile the Eulerian PV analysis with the angular momentum perspective. To this end, angular momentum (Fig. 4c) and the zonal pressure gradient (Fig. 4d) were tracked along all trajectories. Based on Eq. (1), we assume that the observed changes in angular momentum are due to the zonal pressure gradient term. Recall the three trajectory pathways (northern, subtropical, and tropical) described in the previous section. The ensuing discussion is structured according to the number of trajectories following each pathway. The few trajectories that reached the subtropical jet from the north gained in angular momentum during the last $48 \mathrm{~h}$ prior to their reaching the jet while moving through an area of strong pressure gradient forcing along the western flank of the breaking wave (Figs. 4c,d).

For the trajectories that moved northward from the equator across Africa while turning anticyclonically, angular momentum was relatively well conserved south of $15^{\circ} \mathrm{N}$, bringing high-angular momentum air into the subtropical jet. From the PV perspective the anticyclone was an area of very low PV (Fig. 4b), and therefore advection from this region led to a strengthening of the PV gradient in the jet area.

The subtropical strand of trajectories comprising the majority of the trajectories first experienced an increase of angular momentum and an accompanying acceleration when the air moved southward along the western flank of a small trough in the subtropical western Atlantic (Fig. 4d). A second, stronger phase of positive angular momentum change occurred over the eastern subtropical Atlantic and Africa (Fig. 4d). This second phase was crucial and linked the extratropical wave breaking event and the formation of the subtropical jet streak in the angular momentum framework. The breaking wave had developed over Europe downstream of a strong extratropical anticyclone (Fig. 4c) with an attendant area of negative $d p / d \lambda$ and hence a positive material change of $M$ between the anticyclone (ridge) and the breaking wave (trough) that reached into the 

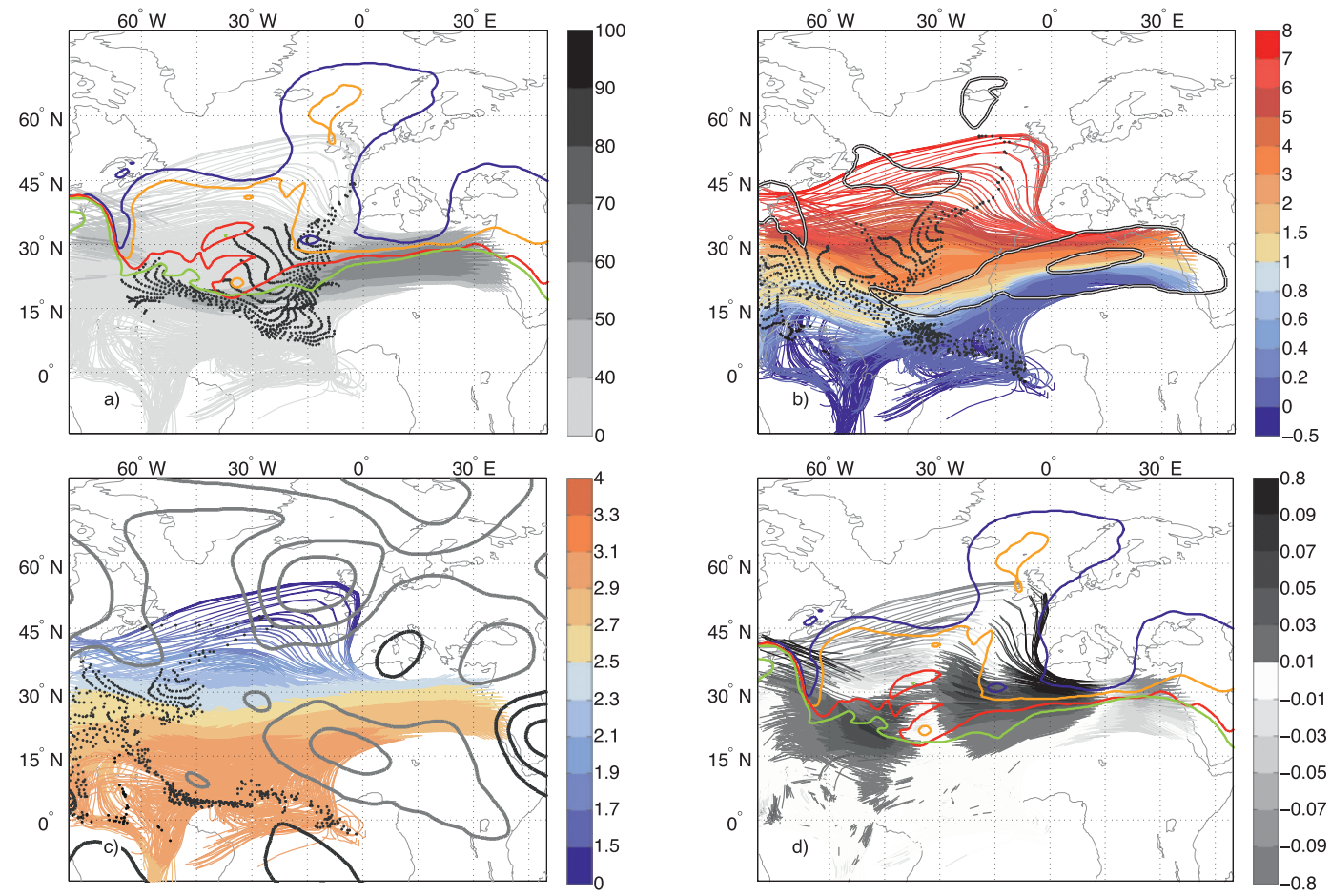

FIG. 4. Backward trajectories started at 1800 UTC 4 Jan from areas where the wind velocity exceeded $40 \mathrm{~m} \mathrm{~s}^{-1}$ on the 345-K isentropic surface in the starting domain (shown as the black rectangle in Fig. 1a). (a) The trajectories are gray shaded according to the local wind velocity $\left(\mathrm{m} \mathrm{s}^{-1}\right)$. The solid colored lines indicate the location of the dynamical tropopause on the several isentropic surfaces (blue: $320 \mathrm{~K}$, yellow: $330 \mathrm{~K}$, red: $340 \mathrm{~K}$, green: $350 \mathrm{~K}$ ). The black dots indicate the location of the trajectories at $-24 \mathrm{~h}$. (b) The trajectories are colored according to their PV value (PVU) and the dots indicate $-48 \mathrm{~h}$. The black and white solid lines indicate the 40,65 , and $75 \mathrm{~m} \mathrm{~s}^{-1}$ wind velocity contours at 1800 UTC 4 Jan. (c) The trajectories are colored according to their angular momentum $\left(10^{9} \mathrm{~s}^{-1}\right)$. The black dots indicate the position at $-72 \mathrm{~h}$. The gray (positive, anticyclonic anomaly) and black (negative, cyclonic anomaly) lines indicate streamfunction anomalies $\left(\mathrm{m}^{2} \mathrm{~s}^{-1}\right)$ to the climatological mean on $200 \mathrm{hPa} 1$ day prior to the arrival of the trajectories. (d) The trajectory shading indicates the change in angular momentum per $6 \mathrm{~h}$ along the trajectory pathway $\left(10^{9} \mathrm{~s}^{-1}\right)$.

subtropics. The ridge-trough couplet and the area of negative $d p / d \lambda$ propagated eastward at a nonnegligible phase speed. As a consequence, the trajectories following the subtropical pathway were accelerated (positive change of $M$ ) for an extended time period (approximately $24 \mathrm{~h}$; see black dots along the trajectories in Fig. 4d).

The area where the PV gradient was enhanced by the breaking wave and where the jet exhibited a local maximum (jet streak) was approximately $25^{\circ}$ wide. The effect of the breaking wave on the subtropical jet over Africa was hence locally prominent but limited in terms of spatial extent and overall effect on the subtropical jet over Africa. This is confirmed by the angular momentum analysis. It is possible to estimate the nonconservation of angular momentum along all trajectories and compare this number with the Eulerian change of angular momentum per unit mass integrated over the subtropical jet on the $345-\mathrm{K}$ isentrope (defined here as wind speed exceeding $40 \mathrm{~m} \mathrm{~s}^{-1}$ ). Between 0000 UTC 3 January and 1800 UTC 4 January this Eulerian change in angular momentum per unit mass was positive in accordance with the acceleration of the jet and amounted to approximately $3 \times 10^{11} \mathrm{~s}^{-1}$.

Recall that the bulk of the nonconservation of angular momentum along the trajectories is due to the pressure gradient effect. The Lagrangian change of angular momentum integrated over time along each trajectory and then summed up across all trajectories is a function of the integration time period. It varied between approximately $3 \times 10^{10} \mathrm{~s}^{-1}$ for the $24 \mathrm{~h}$ before the trajectories arrived in the jet, a maximum of $7 \times 10^{10} \mathrm{~s}^{-1}$ for the last $60 \mathrm{~h}$ and $-6 \times 10^{9} \mathrm{~s}^{-1}$ for the entire duration of the trajectories $(144 \mathrm{~h})$. Although the Eulerian and the Lagrangian values cannot be directly compared, the orders of magnitude can still be appreciated. The variation in angular momentum is on the order of $10 \%$ of the observed Eulerian change and the pressure gradient effects 

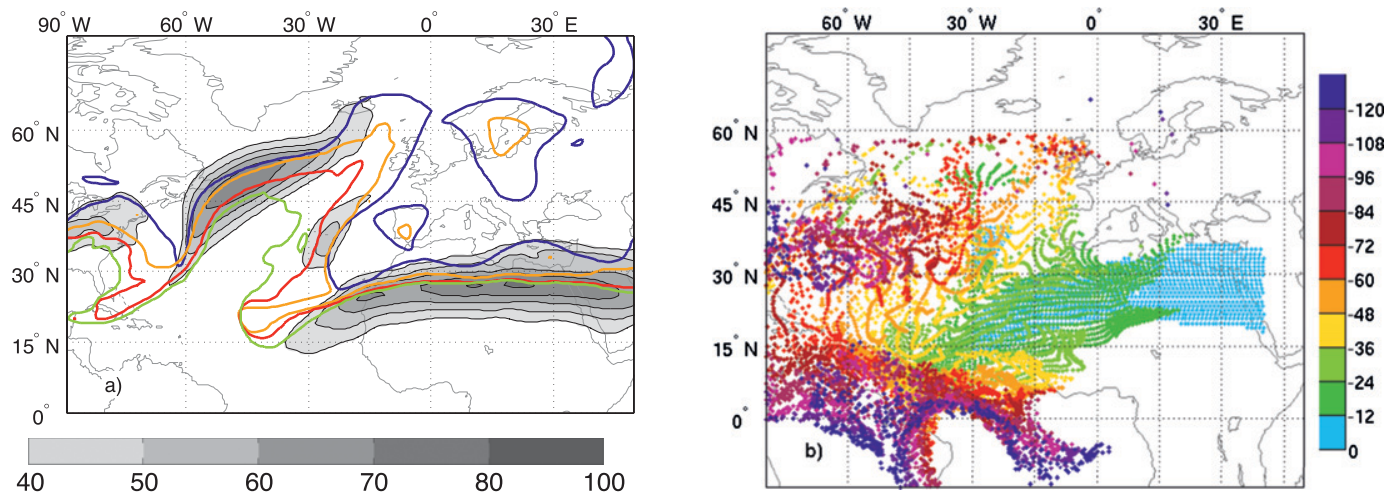

FIG. 5. (a) As in Fig. 3, but at 0000 UTC 9 Jan. (b) The dots indicate the location of the trajectories at successively large time lags prior to 0000 UTC 9 Jan.

were hence of secondary importance compared to the angular momentum export from the tropics.

Climatologically the region over Europe and the Mediterranean is a preferred area for anticyclonic wave breaking in the extratropics during wintertime (e.g., Martius et al. 2007) and the subtropical jet acceleration mechanism described here is therefore likely to occur on a regular basis. When considering the climatological mean structure of the subtropical jet over Africa, its cumulative effect is therefore potentially nonnegligible.

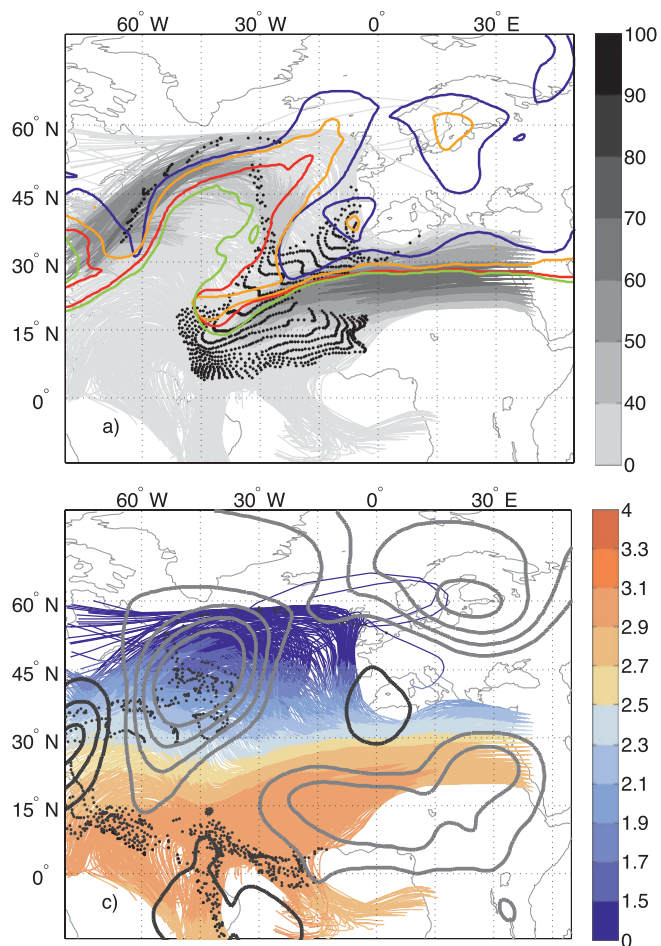

\section{b. Subtropical wave breaking}

In this section the effect of a subtropical wave breaking event on the subtropical jet is illustrated exemplarily. Compared to extratropical wave breaking events the spatial scale of these wave breaking events is typically larger and areas of pressure gradient forcing potentially reach farther equatorward. Between 7 and 9 January 2006 a large-scale anticyclonic wave breaking event occurred over the subtropical eastern Atlantic and over western Africa. At the same time a strong subtropical jet

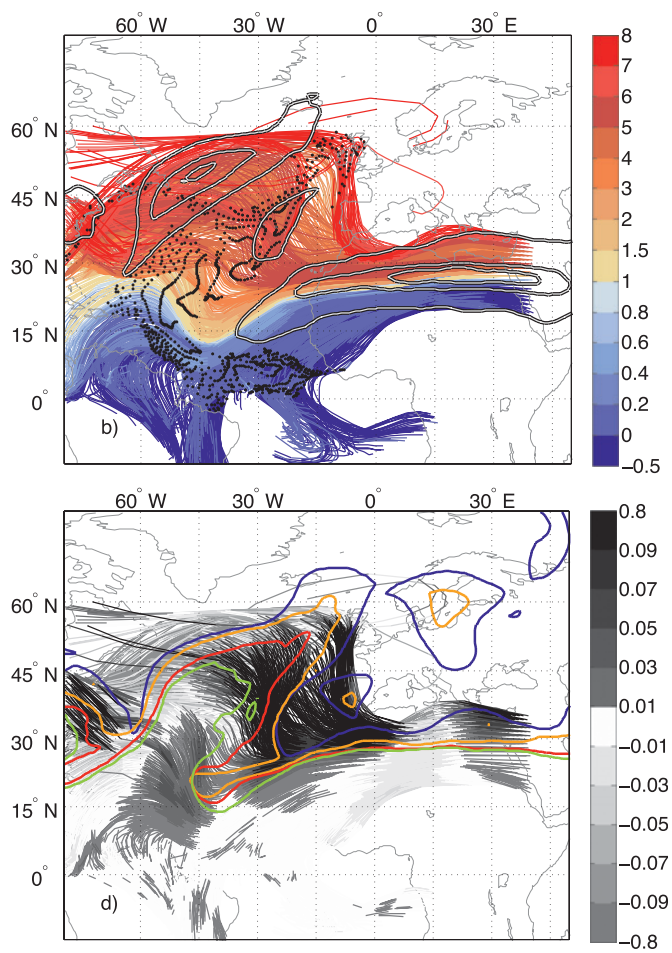

FIG. 6. As in Fig. 4, but at 0000 UTC 9 Jan. 
that extended from $25^{\circ} \mathrm{W}$ to the Arabian Peninsula was accelerated, and maximum winds increased from 73 to $81 \mathrm{~m} \mathrm{~s}^{-1}$ (Fig. 5a). From the PV perspective the area of strong winds was collocated with a longitudinally elongated area of strong PV gradients along the southern flank of the breaking wave. In this area anomalously high-PV stratospheric air was in close proximity to tropospheric low PV in the south. In contrast to the previous case, the wave breaking event spanned the entire tropopause region from the extratropics to the subtropics and the extratropical ridge and the extratropical jet were much stronger.

A significant fraction of the back trajectories started at 0000 UTC 9 January reached the subtropical jet from the north (approximately $40 \%$ ). The rest of the trajectories took a subtropical pathway (approximately 16\%) or propagated northward from the tropics (approximately $44 \%$ ) (Figs. 5b and 6). The upper-level flow over the central North Atlantic was dominated by the breaking wave (negative streamfunction anomaly) sandwiched between a strong ridge (anticyclone) upstream over the extratropical Atlantic and a tropical anticyclone over North Africa (Fig. 6c). The angular momentum was relatively well conserved in the tropical region and along the western flank of the anticyclone in the subtropics (Figs. 6c,d). Only around $10^{\circ} \mathrm{E}$, in the center of the anticyclonic streamfunction anomaly over West Africa, did a slight reduction of the angular momentum due to pressure gradients occur (Figs. 6c,d). Potentially, this anticyclonic circulation formed in response to convective heating over equatorial Africa in early January (Fig. $7 \mathrm{a}$, label C) and interacted with the breaking wave in the subtropics. Very low PV characterized the air parcels that arrived in the tropospheric part of the subtropical jet. They had crossed the equator at upper levels and moved farther northward along the eastern flank of the breaking wave. Two bundles of a few trajectories show an ascent from the surface to the tropopause in areas of intense convection over South America (Figs. 7a,b, labels A and B). Tropical convection and the flow field of the breaking wave forced the advection of low-PV and high-angular momentum air from the tropics toward the subtropical jet (Figs. 6b,c).

In the extratropics the trajectories' angular momentum decreased upon entering the ridge upstream of the breaking wave and increased on its way south along the eastern flank of the ridge (Fig. 6d). Air parcels taking the subtropical pathway were influenced by the "far field" pressure gradient effect of the strong extratropical anticyclone. The link between the PV perspective and the angular momentum conservation perspective in the extratropics is hence slightly different than in the previous example. In the previous example almost no
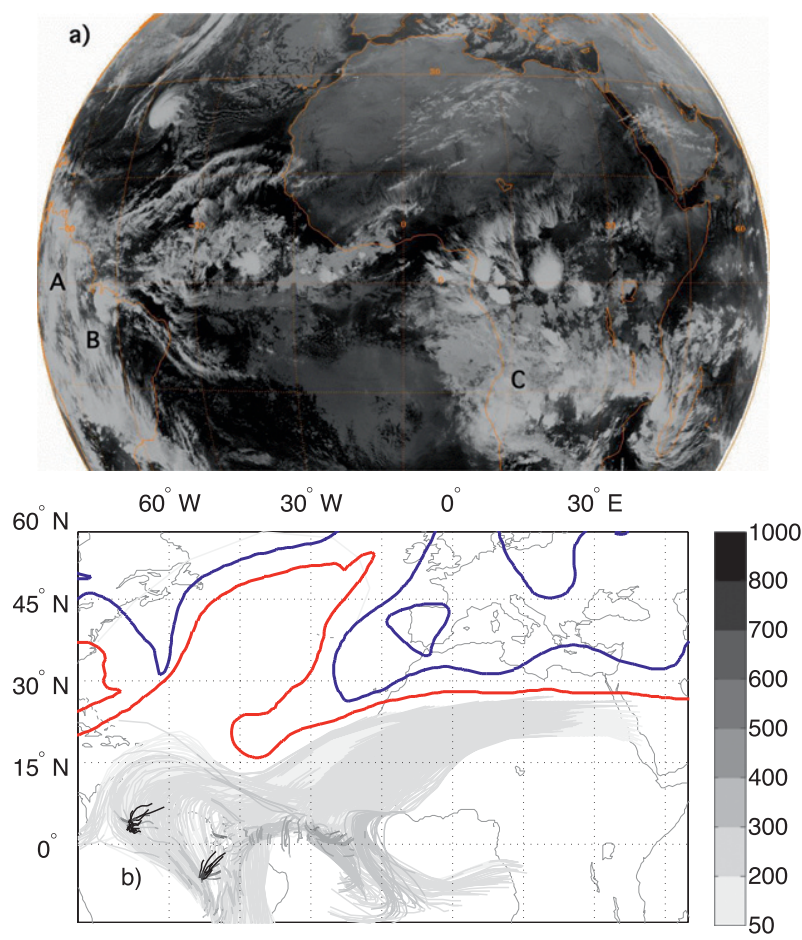

FIG. 7. (a) An IR picture from Meteosat (second generation) taken at 2345 UTC 2 Jan. The labels indicate the position of the convective systems mentioned in the text. (b) Back trajectories started on the $345-\mathrm{K}$ isentropic surface at 0000 UTC 9 Jan from areas where the wind velocity exceeded $40 \mathrm{~m} \mathrm{~s}^{-1}$ and the PV was less than $0.5 \mathrm{PVU}$. The gray shading indicates the pressure along the trajectories $(\mathrm{hPa})$, and the colored lines the location of the dynamical tropopause at 320 (blue line) and $340 \mathrm{~K}$ (red line) on 0000 UTC 9 Jan.

trajectories reached the subtropical jet from the extratropics. In this example, because of the stronger extratropical anticyclone a significant fraction of trajectories reached the jet from the extratropics and the angular momentum of these air parcels was significantly and directly affected by the extratropical systems.

The effect of the extratropical trajectories on the angular momentum budget can again be evaluated semiquantitatively from the trajectory analysis. The total Eulerian angular momentum change of the subtropical jet over Africa for the time period between 0600 UTC 7 January and 0000 UTC 9 January amounted to $4 \times$ $10^{11} \mathrm{~s}^{-1}$. This number can be compared to the total change of angular momentum change along the trajectories for different time intervals prior to reaching the jet. The mean accumulated angular momentum along all of the trajectories amounted to $7.4 \times 10^{10} \mathrm{~s}^{-1}$ during the 24-h interval before the arrival in the subtropical jet, reached a maximum of $1.7 \times 10^{11} \mathrm{~s}^{-1}$ during the last $54 \mathrm{~h}$ prior to the arrival in the jet (corresponding to almost $50 \%$ of the total Eulerian change), and decreased 

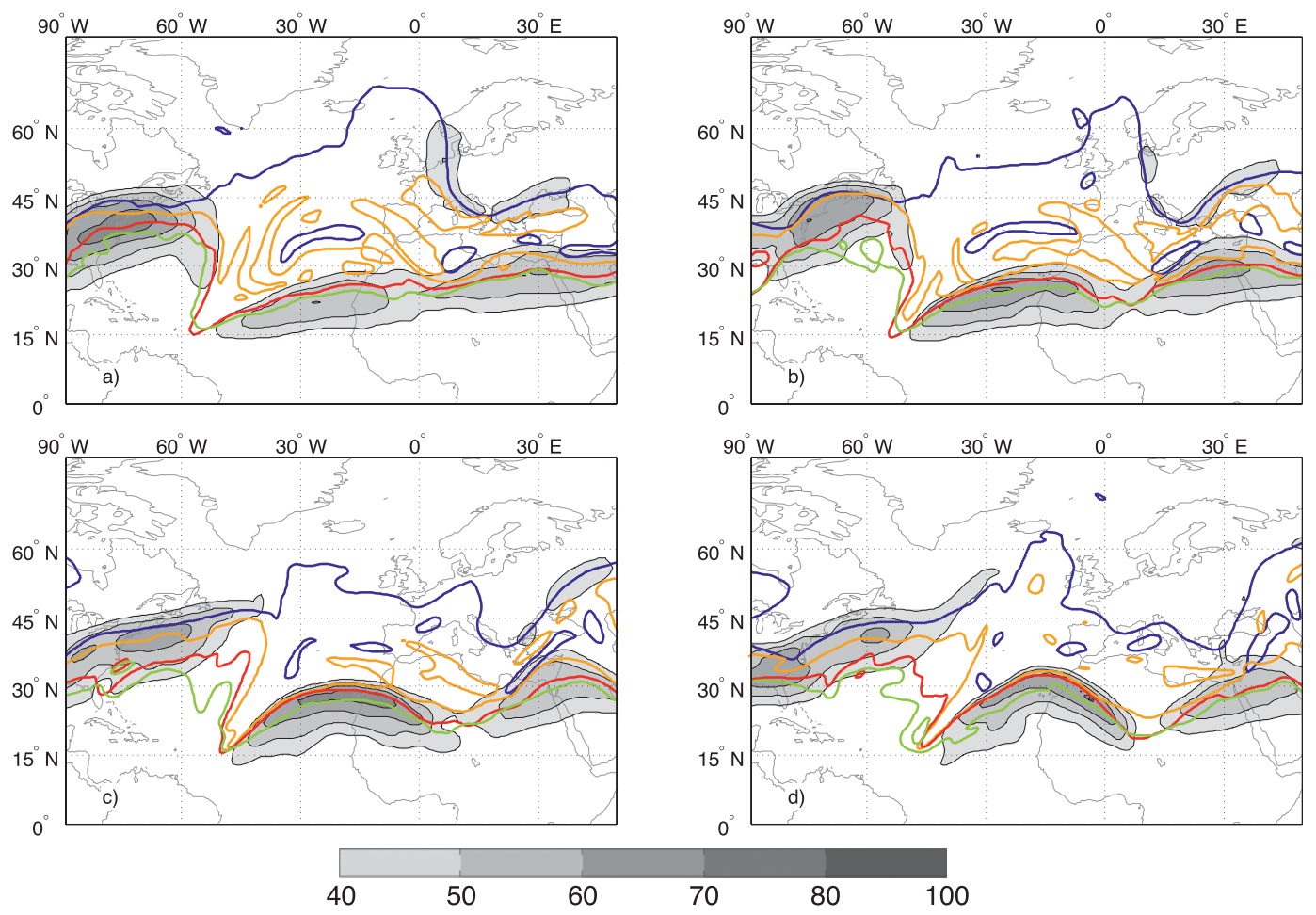

FIG. 8. As in Fig. 3, but at (a) 0000 UTC 18 Dec, (b) 1200 UTC 18 Dec, (c) 0000 UTC 19 Dec, and (d) 1200 UTC 19 Dec.

to almost zero $144 \mathrm{~h}$ back in time. The 54-h time lag corresponds approximately to the time when the extratropical trajectories were located at the northernmost part of the ridge and entered the area of positive pressure gradient forcing (Figs. 5b and 6d), so this was a more dominant process than in the previous example.

\section{Subtropical wave breaking and convective influence}

In this section the effect of subtropical diabatic processes on the upper-level PV budget and hence potentially on the subtropical jet are addressed. We selected the episode with the strongest diabatic heating effects on the air parcels that ended in the tropospheric part of the subtropical jet over Africa in the winter of 2005/06. Between 17 and 20 December 2005 an anticyclonic wave breaking event occurred over the subtropical North Atlantic reaching far into the tropics (Fig. 8). At that time the subtropical and the extratropical tropopause were well separated and the wave breaking event happened only in the subtropics. At 0000 UTC 18 December a relatively weak (maximum of $59 \mathrm{~m} \mathrm{~s}^{-1}$ ) subtropical jet extended from the subtropical central Atlantic into Asia along the southern flank of the breaking wave (Fig. 8a). Over the next $36 \mathrm{~h}$ the jet broke up into two individual jet streaks collocated with two ridges and accelerated to $70 \mathrm{~m} \mathrm{~s}^{-1}$. This happened in conjunction with an increase in the PV gradient along the downshear flank of the breaking wave (Fig. 8d).

The majority of the air that reached the subtropical jet streaks on $345 \mathrm{~K}$ followed a path across the subtropical Atlantic along the subtropical tropopause (Fig. 9a). A small strand of trajectories joined the subtropical jet from the north crossing western Europe. The breaking wave was associated with a strong cyclonic streamfunction anomaly and the subtropical streamfunction anomalies were arranged in a wavelike manner along the subtropical jet across the Atlantic (Fig. 9c).

In contrast to the previously discussed cases, areas of strong latitudinal pressure gradients, altering the angular momentum along the trajectories, extended deep into the subtropics, leading to a wavelike pattern of areas of angular momentum reduction and increase in accordance with the wave pattern observed in the streamfunction anomalies (Figs. 9c,d). The positive pressure forcing along the western flank of the breaking wave (upper-level trough) reached a larger amplitude than the negative forcing along its eastern flank and reached farther into the tropics than in the previous examples. 

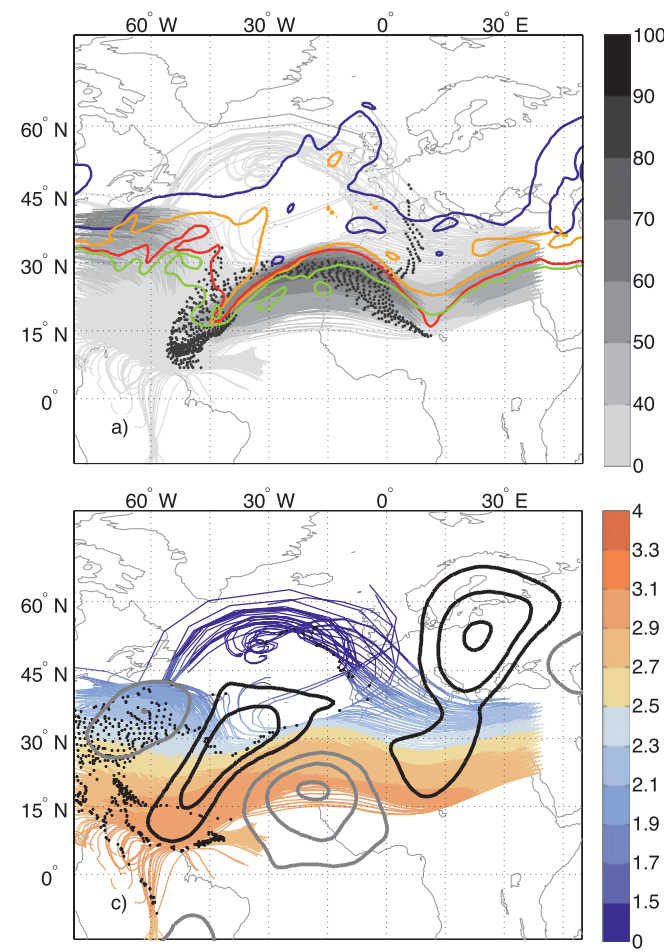
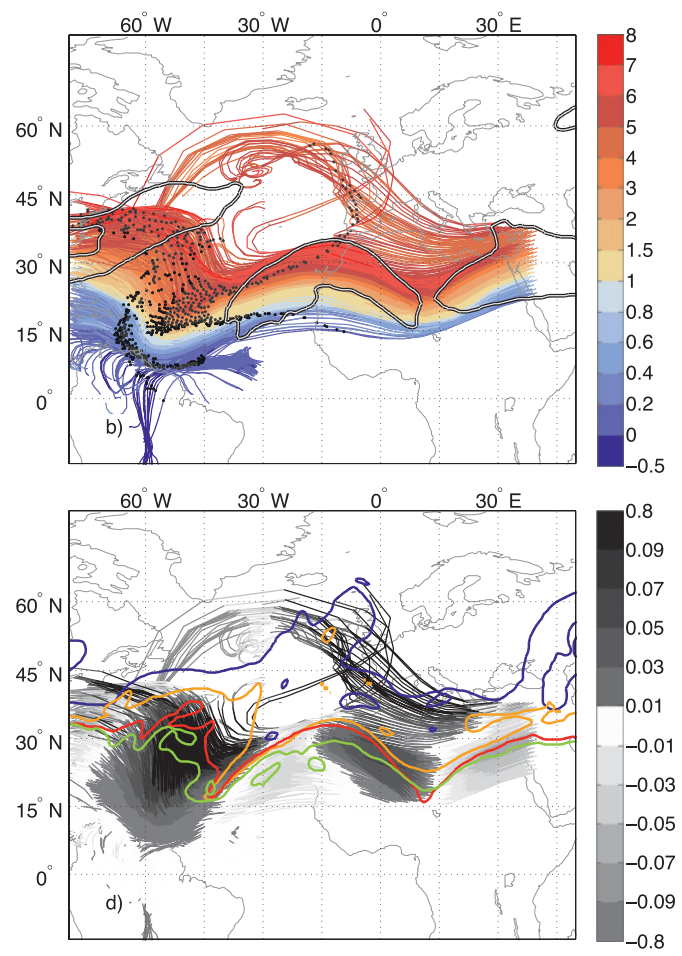

FIG. 9. As in Fig. 4, but at 1800 UTC 19 Dec 2005.

A convectively active zone was located downstream of the breaking wave between 18 and 20 January (Fig. 10c). Rossby waves that break in the subtropics can trigger convection through forced lifting along their downshear flank and destabilization of the atmosphere (e.g., Kiladis and Weickmann 1992; Funatsu and Waugh 2008). This flow configuration is not uncommon in the Atlantic and eastern Pacific and typical for the formation of a tropical plume and upper-level jet streaks (e.g., Knippertz 2005). The effect of this flow configuration on the PV distribution along the southern flank of the subtropical jet stream is twofold: (i) low PV can be advected northward at upper levels along the eastern flank of the breaking wave (see also previous case) and (ii) strong diabatic processes can potentially lead to a depletion of PV in the outflow region of the diabatic system where air parcels cross an area of negative vertical heating gradients (e.g., Wernli and Davies 1997; Kiladis 1998) and thereby enhance the isentropic PV gradient across the jet. Trajectories starting in the low-PV area $(<0.1 \mathrm{PVU})$ in the tropospheric part of the subtropical jet on the 340 - and $345-\mathrm{K}$ isentropes indicate that the fraction of trajectories that experienced strong lifting decreased with height (not shown). The following discussion focuses on the $340-\mathrm{K}$ trajectories and is therefore an indication of the upper limit of the diabatic influence on the subtropical jet stream. The qualitative behavior of the trajectories ending on the 340- and 345-K levels was similar and independent of the PV threshold used for selecting the low-PV trajectories.

An overlay of the trajectory pathways through the convective system on IR satellite imagery shows that the lifting process is very well represented in the ERAInterim data (Fig. 11a). These trajectories experienced strong lifting (approximately $400 \mathrm{hPa}$ associated with a diabatic heating of $18 \mathrm{~K}$ ) during the last $48 \mathrm{~h}$ before they reached the subtropical jet. This lifting occurred between $5^{\circ}$ and $25^{\circ} \mathrm{N}$ (Figs. 11a,c). This is in contrast to the situation on 9 January, where the lifting was observed in the Southern Hemisphere and the inner tropics (Figs. 6 and 7). The PV evolution along the trajectories is shown in Fig. 11d. Despite the very active heating and diabatic processes, the PV was relatively constant along the trajectories, with a minor decrease of approximately 0.07 PVU averaged over all trajectories during the last $36 \mathrm{~h}$ of the time period. These results agree with the results of a trajectory analysis presented in Knippertz (2005), where changes in the PV along the trajectories ending in a tropical plume were very small as well. The results differ, however, quite substantially from similar analyses carried out in the extratropics where a significant increase in PV upon entering the area of maximum heating is followed by a decrease in PV in the outflow region (e.g., Wernli and Davies 1997). The main reason 

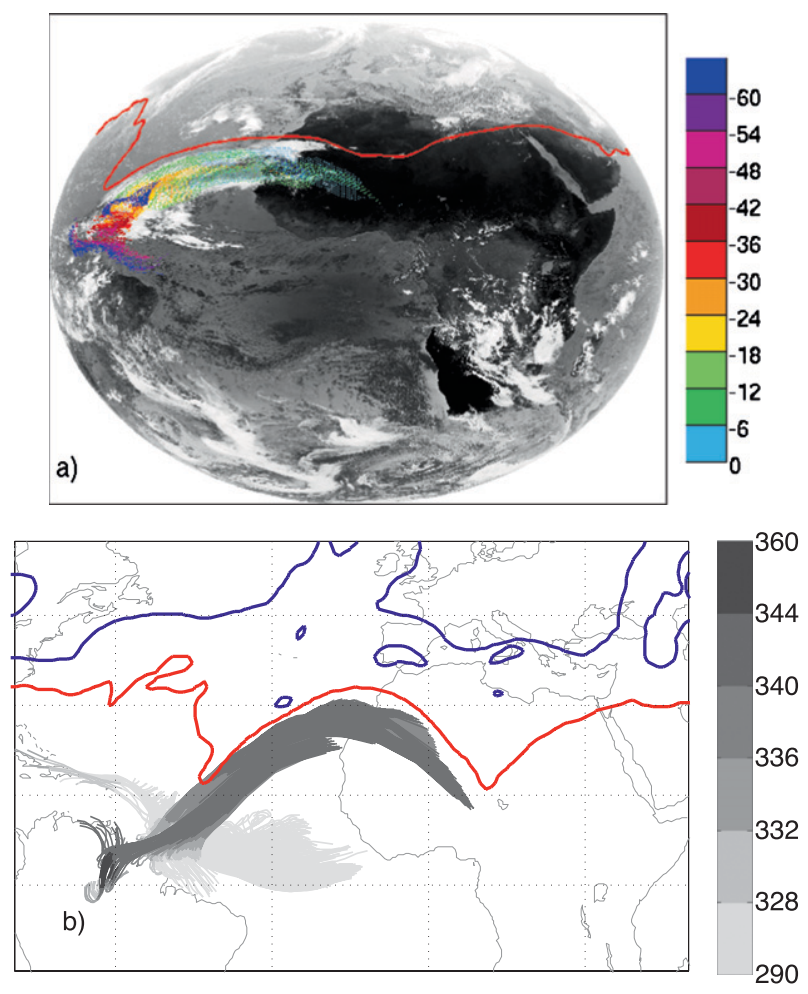

FIG. 10. (a) Meteosat IR picture taken at 1200 UTC 18 Dec and the location of the trajectories ending up in the low-PV air to the south of the subtropical jet. The colors indicate the time lag to the arrival of the air parcels in the subtropical jet. (b) Back trajectories started from the tropospheric part of the subtropical jet $(\mathrm{PV}<0.1$ PVU) at 1800 UTC 19 Dec colored by their potential temperature values (gray shading). The solid lines indicate the dynamical tropopause on 340 (red line) and $320 \mathrm{~K}$ (blue line).

for this might be the small absolute vorticity values close to the equator, which lead to very small material changes in PV in regions of cloud diabatic heating (note the fairly constant values of PV in Fig. 11d during the first 4 days). The small negative PV changes at upper levels (i.e., in a region with a negative vertical gradient of the latent heating) occurred at $15^{\circ}-20^{\circ} \mathrm{N}$ (Fig. 11c), where planetary vorticity was increasing.

It can be said that for this case the effect of strong diabatic heating in the subtropics on the upper-level PV distribution is mainly indirect through advection of low$\mathrm{PV}$ air from the tropics by the outflow of the convective system and not via direct diabatic PV alteration.

\section{Generalization of the case study results}

The three case studies presented in the previous section showed that extratropical dynamics can have a nonnegligible effect on the acceleration (and potentially deceleration) of the subtropical jet over Africa and that diabatic processes in the subtropics mainly have an indirect effect on the upper-level PV distribution. To generalize these findings the behavior of all trajectories reaching the subtropical jet during the winter season of 2005/06 is summarized in Fig. 12. These trajectories were selected using the same criteria (starting domain, wind speed) as in the case studies. Shown are the mean temporal evolution and the variability of angular momentum (Fig. 12a), the pressure gradient forcing term (Fig. 12b), the latitudinal position (Fig. 12c), the pressure (Fig. 12d), the PV (Fig. 12e), and the zonal wind (Fig. 12f) for five groups of trajectories. The trajectories were stratified into these groups according to the PV value of the air in the subtropical jet at the starting time. Three categories of stratospheric PV values (i.e., $\mathrm{PV}>2 \mathrm{PVU}$ at $t=0$ ) were chosen, containing approximately $41 \%$ of all the trajectories, and two categories of tropospheric PV values for the remaining $59 \%$. $^{1}$ The width of the lines in Fig. 12 is proportional to the number of trajectories in each category.

The curves exhibit three distinct types of behavior. The first type occurs for the stratospheric trajectories with the largest $\mathrm{PV}$ values at $t=0$ (PV $>4 \mathrm{PVU})$. They arrive in the jet at $30^{\circ} \mathrm{N}$ from the extratropics (Fig. 12c, light gray lines). The zonal wind velocity of these air parcels is approximately $30 \mathrm{~m} \mathrm{~s}^{-1}$ prior to their acceleration into the jet (Fig. 12f), and they gain substantially in angular momentum during the $48 \mathrm{~h}$ before reaching the subtropical jet (approximately $4 \times 10^{8} \mathrm{~s}^{-1}$ or $20 \%$ ) while passing through areas of strong positive pressure forcing (Figs. $12 a, b)$. The 48 -h time interval of positive pressure gradient forcing corresponds to the time when the air parcels are moving southward. Examples of these trajectories are found in the first two cases (Figs. 4 and 6). Approximately $18 \%$ of all trajectories follow this pathway.

The second type corresponds to air parcels with PV values below 1 PVU at the start time of the trajectories (i.e., to air parcels located in the tropospheric part of the subtropical jet stream). The largest fraction of trajectories (41\%) follows this pathway. These air parcels reach the subtropical jet from the inner tropics. Their angular momentum decreases slightly (by approximately $1.5 \times$ $10^{8} \mathrm{~s}^{-1}$ or $5 \%$ ) during the $24 \mathrm{~h}$ before reaching the jet when the trajectories leave the inner tropics, move poleward by approximately $10^{\circ}$, and are subjected to negative pressure forcing (Fig. 12). Concomitantly they gain approximately $45 \mathrm{~m} \mathrm{~s}^{-1}$ in zonal wind speed during the $48 \mathrm{~h}$ before reaching the subtropical jet through the conservation of angular momentum.

\footnotetext{
${ }^{1}$ The following groups were chosen: $\mathrm{PV}>4 \mathrm{PVU}, 3<\mathrm{PV}<4$ PVU, $2<\mathrm{PV}<3$ PVU, $1<\mathrm{PV}<2$ PVU, and PV $<1$ PVU. The choice of $\mathrm{PV}$ categories is to a certain degree arbitrary.
} 

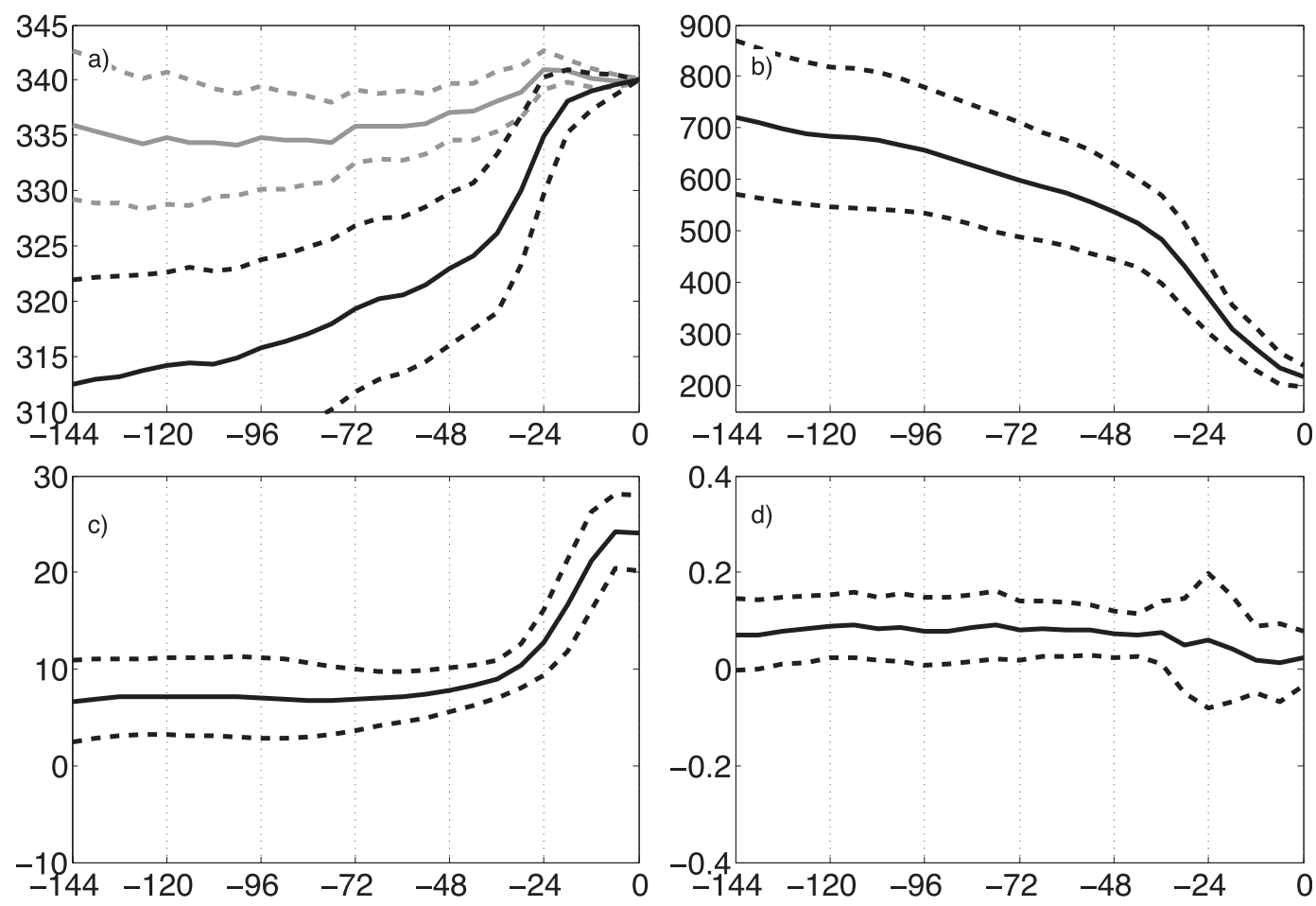

FIG. 11. Statistics of (a) $\theta$ (black) and $\theta_{e}$ (gray), (b) pressure, (c) latitude, and (d) PV along the trajectories started on $340 \mathrm{~K}$ at 1800 UTC 19 Dec. Mean values are indicated by the solid lines and standard deviations by the dashed lines.

Subtropical pathways characterize the groups in between. These air parcels correspond to the third group and they experience northward and southward displacements with attending positive and negative changes in angular momentum linked to variations in the pressure gradient forcing term. During the 48-24 h before reaching the jet they are accelerated in the zonal direction from approximately 30 to $50 \mathrm{~m} \mathrm{~s}^{-1}$ (Fig. 12f). These trajectories therefore tend to be located in a stronger zonal flow, maybe even a jet, before reaching the subtropical jet.

Overall the air parcels do not experience substantial vertical motion during the 6 days prior to reaching the subtropical jet and are located roughly at $200 \mathrm{hPa}$ (Fig. 11d). Few exceptions occur for trajectories that reach the subtropical jet from the south. Some of them are (strongly) lifted prior to reaching the jet. Nevertheless, the majority of the air parcels in the Hadley circulation need more than the 6 days shown here to ascend from the surface and reach the winter hemisphere subtropical jet. This trajectory analysis also indicates that the pathway described in section 4 , with air parcels being lifted from the surface to the tropopause along the downstream flank of an upper-level trough in the western North Atlantic, is only relevant for a small fraction of trajectories.
The temporal evolution of PV along the trajectories is shown in Fig. 12e. The PV is almost perfectly conserved for all trajectories, supporting the conclusion from the last case study that the direct diabatic alteration of upper-level PV is not a relevant factor for the dynamics of the subtropical jet.

A similar climatological analysis is carried out for the days when the subtropical jet is especially weak or strong (maximum and minimum 10\% of the area-averaged wind speed). It reveals that for these days of extreme jets (exceptionally weak or strong), the characteristics of the individual trajectory groups are very similar to the climatology described above (not shown). The fraction of trajectories following each pathway, however, varies substantially (Fig. 13). On days with a very weak jet stream over Africa the majority of the trajectories fall into the "subtropical" groups (51\%) and very few $(6.5 \%)$ reach the subtropical jet from the extratropics. On days with a very strong jet stream over Africa, on the other hand, a substantial fraction of trajectories from the deep tropics $(49.2 \%)$ and the extratropics $(20.1 \%)$ reach the subtropical jet. This is equivalent to an increased convergence of tropospheric low-PV air and particularly stratospheric high PV air in the subtropics. The strong variability of the extratropical contribution to the jet 

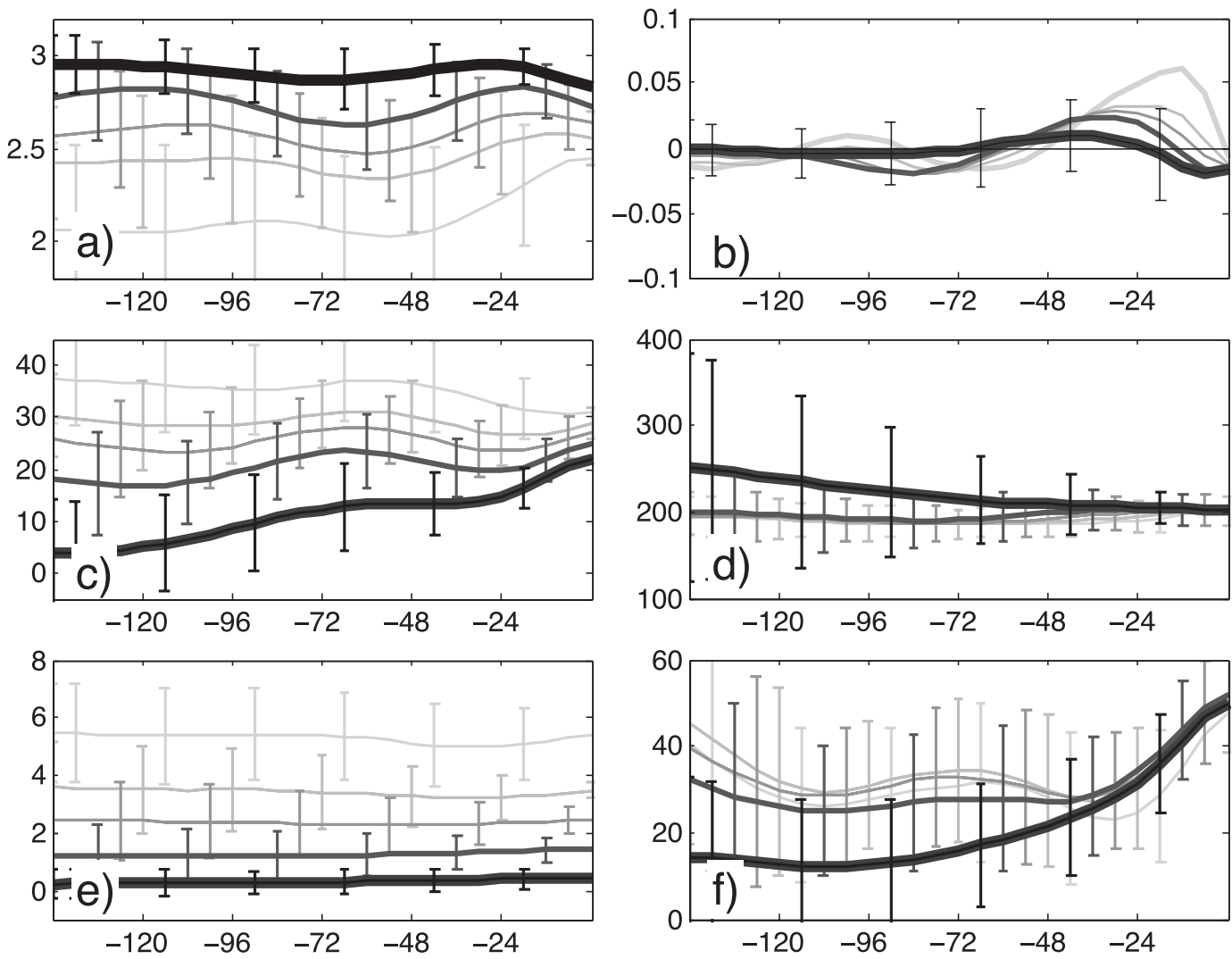

FIG. 12. Time evolution of (a) the angular momentum $\left(10^{9} \mathrm{~s}^{-1}\right)$, (b) the pressure forcing per $6 \mathrm{~h}\left(10^{9} \mathrm{~s}^{-1}\right)$, (c) the latitude, (d) the height (hPa), (e) PV (PVU), and (f) zonal wind speed $\left(\mathrm{m} \mathrm{s}^{-1}\right)$ averaged over all trajectories started from the subtropical jet over Africa in the winter 2005/06 season. Error bars indicate plus/minus one standard deviation. The variability in (b) was too large to fit into the panel. The trajectories were grouped according to their $\mathrm{PV}$ value at $t=0$ [black line: PV $<1 \mathrm{PVU}$; dark gray: $1<\mathrm{PV}<2 \mathrm{PVU}$; medium gray: $2<\mathrm{PV}<3 \mathrm{PVU}$; light gray: $3<\mathrm{PV}<4$ PVU; lightest gray: PV $>4$; see PV data in (e)].

stream suggests an important role of the extratropical dynamics for jet variability.

\section{Summary and discussion}

The central topic of this paper is the study of the dynamical processes that govern the synoptic-scale variability of the Northern Hemisphere wintertime subtropical jet over Africa. The subtropical jet over Africa is a "pure" subtropical or shallow jet with the baroclinicity concentrated at upper levels. Three example cases, illustrating different types of forcing mechanisms, are presented and discussed from both a PV and an angular momentum conservation point of view. Backward trajectories were started from the subtropical jet and PV and angular momentum was traced along the trajectories. This allows us to estimate the conservation and nonconservation of angular momentum due to zonal pressure gradient forcing and to link the PV and the angular momentum perspectives. A "climatological" analysis of all trajectories that reached the subtropical jet over Africa during the winter season 2005/06 complemented the case study results.

In all three cases, synoptic-scale wave breaking in the extratropics and the subtropics contributed to the acceleration of the subtropical jet. This can be understood from a PV point of view by the meridional stirring and rearrangement of PV by the wave breaking. A southward transport of extratropical, stratospheric high-PV air results in enhanced PV gradients along the subtropical tropopause and hence a strengthening of the jet. Relevant for the angular momentum budget are the strong zonal pressure gradients that accompanied the wave breaking events in the extratropics and to a lesser degree in the subtropics. The pressure gradient forcing increases the angular momentum of air that reaches the subtropical jet from the extratropics and the subtropics.

The analysis for the entire winter season shows that extratropical forcing of the subtropical jet is particularly relevant during time periods when the jet is strong. In the mean approximately $18 \%$ of the trajectories reach 

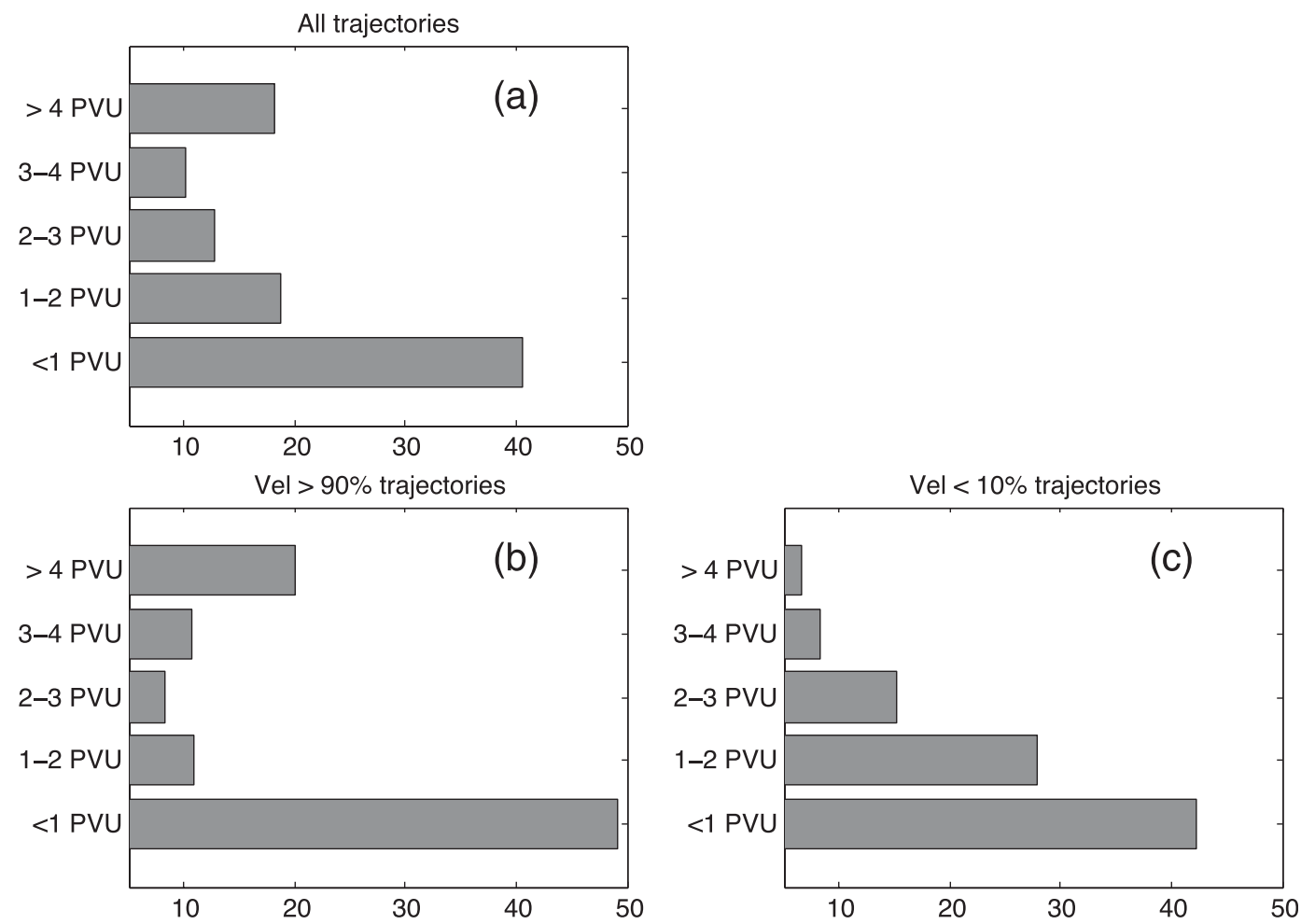

FIG. 13. Fraction of trajectories falling into the different PV categories (see $y$ axis and text for details) for (a) all trajectories, (b) the time instances with the strongest $10 \%$ of jet streams, and (c) the time instances with the weakest $10 \%$ of jet streams.

the subtropical jet over Africa from the extratropics and $41 \%$ from the deep tropics. However, the longitudinal section over the eastern Atlantic and Africa coincides with the climatological maximum of breaking waves in the extratropics (Martius et al. 2007) and the relevance of extratropical forcing is likely to be smaller in other parts of the world. The jet over Asia, for example, is strongly influenced by monsoon dynamics and by systems of organized tropical convection such as the MaddenJulian oscillation.

Wave breaking in the subtropics can trigger convection and the effect of convection was analyzed in section 4 with a focus on the direct diabatic effects on the upperlevel PV budget. In the presented case the direct diabatic effects were of secondary importance for the upper-level PV evolution compared to the advection of low PV by the northward flow along the eastern flank of the breaking wave and by the outflow from the diabatic region. Since, given a particular profile of latent heating, the diabatic alteration of PV is proportional to the absolute vorticity (e.g., Hoskins 1991), the low values of planetary vorticity in the tropics and subtropics might explain the small effect of the diabatic processes on the PV. As a side note, the trajectory pathway corresponding to the "diabatic case" described in section 4 , where high- $\theta_{e}$ and initially low- $\theta$ air is being transported poleward and lifted by an equatorward moving upper-level trough could correspond to the moist air pathway described by Pauluis et al. (2008).

Having established a link between the angular momentum and the PV framework, it is interesting to briefly discuss links to the momentum flux framework. The "wave breaking in the subtropics" flow configuration has been described from a momentum flux point of view by Kiladis (1998). He presented composites of the eddy meridional momentum fluxes over a number of events. The composites show an overall poleward directed flux of westerly momentum, in accordance with the anticyclonic character of the breaking wave. Two maxima in the meridional momentum fluxes are located in the extratropics and in the subtropics, respectively, accompanied by a divergence of the fluxes, indicating westerly acceleration of both the subtropical and the extratropical jet (Kiladis 1998, his Fig. 9). In his study, the subtropical jet was accelerated because of westerly momentum flux from the tropics.

This paper focused on the winter season only. Large seasonal variations in the relative importance of extratropical and subtropical eddy forcing versus tropical forcing of the Hadley circulation and hence the 
subtropical jet have been reported by Bordoni and Schneider (2010), with the equinox seasons being dominated by eddy forcing and the winter being dominated by angular momentum-conserving flow characteristics. This is in agreement with the summary of the trajectory analysis presented in section 5, underlining the important role of the tropical pathways along which the air experiences only minor changes in angular momentum. It would be interesting to extend the analyses presented in this paper to other seasons. The subtropical jet over Africa is unique in its characteristics in the Northern Hemisphere and it would be very illuminative to extend the analysis to other geographical areas.

Acknowledgments. We thank Huw Davies for invaluable advice, Jeffrey Annis for his help with a pilot study to this project, Daniela Domeisen for proofreading, George Kiladis and an anonymous reviewer for their valuable feedback and suggestions, and Meteo Swiss for granting access to the ERA-Interim data set. The satellite images were downloaded from the National Climatic Data Center. Publication costs have been covered by the German Research Foundation (DFG) as part of the research unit PANDOWAE (FOR 896).

\section{REFERENCES}

Bordoni, S., and T. Schneider, 2010: Regime transitions of steady and time-dependent Hadley circulations: Comparisons of axisymmetric and eddy-permitting simulations. J. Atmos. Sci., 67, 1643-1654.

Davies, H. C., 1981: An interpretation of sudden warmings in terms of potential vorticity. J. Atmos. Sci., 38, 427-445.

Dee, D. P., and Coauthors, 2011: The ERA-Interim reanalysis: Configuration and performance of the data assimilation system. Quart. J. Roy. Meteor. Soc., 137, 553-597, doi:10.1002/ qj.828.

Dritschel, D. G., and M. E. McIntyre, 2008: Multiple jets as PV staircases: The Philips effect and the resilience of eddytransport barriers. J. Atmos. Sci., 65, 855-874.

Feldstein, S. B., and U. Dayan, 2008: Circumglobal teleconnections and wave packets associated with Israeli winter precipitation. Quart. J. Roy. Meteor. Soc., 134, 455-467.

Funatsu, B. M., and D. W. Waugh, 2008: Connections between potential vorticity intrusions and convection in the eastern tropical Pacific. J. Atmos. Sci., 65, 987-1002.

Gill, A. E., 1980: Some simple solutions for heat-induced tropical circulation. Quart. J. Roy. Meteor. Soc., 106, 447-462.

— 1982: Atmosphere-Ocean Dynamics. Academic Press, 645 pp.

Held, I. M., and A. Y. Hou, 1980: Nonlinear axially symmetric circulations in a nearly inviscid atmosphere. J. Atmos. Sci., 37, 515-533.

— , and P. Phillips, 1990: A barotropic model of the interaction between the Hadley cell and a Rossby wave. J. Atmos. Sci., 47, 856-869.

Hoskins, B. J., 1991: Towards a PV- $\theta$ view of the general circulation. Tellus, 43, 27-35.
— - and D. J. Karoly, 1981: The steady linear response of a spherical atmosphere to thermal and orographic forcing. J. Atmos. Sci., 38, 1179-1196.

Isotta, F., O. Martius, M. Sprenger, and C. Schwierz, 2008: Longterm trends of synoptic-scale breaking Rossby waves in the Northern Hemisphere between 1958 and 2001. Int. J. Climatol., 28, 1551-1562, doi:10.1002/joc.1647.

Kiladis, G. N., 1998: Observations of Rossby waves linked to convection over the eastern tropical Pacific. J. Atmos. Sci., 55, 321-339. - and K. M. Weickmann, 1992: Extratropical forcing of tropical Pacific convection during northern winter. Mon. Wea. Rev., 120, 1924-1938.

Knippertz, P., 2005: Tropical-extratropical interactions associated with an Atlantic tropical plume and subtropical jet streak. Mon. Wea. Rev., 133, 2759-2776.

Koch, P., H. Wernli, and H. C. Davies, 2006: An event-based jetstream climatology and typology. Int. J. Climatol., 26, 283-301.

Lee, S., 1997: Maintenance of multiple jets in a baroclinic flow. J. Atmos. Sci., 54, 1726-1738.

— , and H.-K. Kim, 2003: The dynamical relationship between subtropical and eddy-driven jets. J. Atmos. Sci., 60, 1490-1503.

Martius, O., C. Schwierz, and H. C. Davies, 2007: Breaking waves at the tropopause in the wintertime Northern Hemisphere: Climatological analyses of the orientation and the theoretical LC1/2 classification. J. Atmos. Sci., 64, 2576-2592.

,$- \ldots$, and $\longrightarrow, 2008$ : Far-upstream precursors of heavy precipitation events on the Alpine south-side. Quart. J. Roy. Meteor. Soc., 134, 417-428.

,-- , and -2010 : Tropopause-level waveguides. J. Atmos. Sci., 67, 866-879.

Matsuno, T., 1966: Quasi-geostrophic motions in the equatorial area. J. Meteor. Soc. Japan, 44, 25-42.

McIntyre, M. E., and T. N. Palmer, 1983: Breaking planetary waves in the stratosphere. Nature, 305, 593-600.

Pauluis, O., A. Czaja, and B. Korty, 2008: The global atmospheric circulation on moist isentropes. Science, 321, 1075-1078.

Ploeger, F., and Coauthors, 2011: Insight from ozone and water vapour on transport in the tropical tropopause layer (TTL). Atmos. Chem. Phys., 11, 407-419.

Reiter, E. R., and L. F. Whitney, 1969: Interaction between subtropical and polar-front jet stream. Mon. Wea. Rev., 97, 432-438.

Rossa, A. M., H. Wernli, and H. C. Davies, 2000: Growth and decay of an extratropical cyclone's PV-tower. Meteor. Atmos. Phys., 73, 139-156.

Schwierz, C., S. Dirren, and H. C. Davies, 2004: Forced waves on a zonally aligned jet stream. J. Atmos. Sci., 61, 73-87.

Seidel, D. J., Q. Fu, W. J. Randel, and T. J. Reichler, 2008: Widening of the tropical belt in a changing climate. Nat. Geosci., 1, $21-24$.

Shuckburgh, E., F. Ovidio, and B. Legras, 2009: Local mixing events in the upper troposphere and lower stratosphere. Part II: Seasonal and interannual variability. J. Atmos. Sci., 66, 3695-3706.

Sprenger, M., M. Croci-Maspoli, and H. Wernli, 2003: Tropopause folds and cross-tropopause exchange: A global investigation based upon ECMWF analyses for the time period March 2000 to February 2001. J. Geophys. Res., 108, 8518, doi:10.1029/ 2002JD002587.

Vallis, G. K., 2006: Atmospheric and Oceanic Fluid Dynamics. Cambridge University Press, 745 pp.

Wernli, H., and H. C. Davies, 1997: A Lagrangian-based analysis of extratropical cyclones. 1 . The method and some applications. Quart. J. Roy. Meteor. Soc., 123, 467-489. 